\title{
The impact of hyperbole on perception of victim testimony
}

Shreyasi Desai

Janet McLean

Claire Lawrence

Ruth Filik

This is the accepted manuscript (c) 2021, Elsevier Licensed under the Creative Commons AttributionNonCommercial-NoDerivatives 4.0 International: http://creativecommons.org/licenses/by-nc-nd/4.0/

\section{(cc) BY-NC-ND}

The published article is available from doi: https://doi.org/10.1016/j.pragma.2021.01.013 
The impact of hyperbole on perception of victim testimony

This research did not receive any specific grant from funding agencies in the public, commercial, or not-for-profit sectors. Declarations of interest: none. 


\begin{abstract}
This paper investigates how individuals perceive hyperbole in victim statements. Despite being one of the most commonly used literary tropes, the comprehension and cognition of hyperbole has been largely ignored in the psycholinguistics literature, and despite detailed literature outlining the emotional behaviour of victims, the use of figurative language has been largely ignored in the forensics literature. In the present study, two experiments were undertaken. In Experiment 1, 32 participants were recruited from groups with forensic experience or training. Participants were presented with 16 victim statements; eight contained a number of hyperbolic phrases and eight contained non-hyperbolic counterparts. After reading each statement, participants were asked to answer questions that would quantify perceived credibility on accounts of belief, sympathy, victim-impact, and likeability. The results from Experiment 1 showed that hyperbolic speech made a significant negative impact on all four credibility measures. In Experiment 2, 32 juryeligible individuals performed the same task. Results from this experiment demonstrated that the use of hyperbole made testimonies more believable and made the victim seem more impacted. Results are discussed in terms of the real-world implications of using hyperbolic language, and individual differences in the comprehension of, and reaction to, figurative statements.
\end{abstract}

Keywords: hyperbole, victim language, figurative language perception 


\section{Introduction}

Primary statements from victims of sexual crime are often highly emotionally charged and may be more accurate about their emotional state than the actual chain of events. Specifically, although emotion and memory biologically stem from two different systems, they interact when intense emotion is evoked in retrieving a memory (Phelps, 2004). That is, emotions can modulate memories to match emotional significance and interpretation of events (Loftus \& Palmer, 1974; Phelps, 2004). In professional settings such as police interrogation rooms or legal court rooms, where social stereotypes ideally should be irrelevant to decision-making, research has shown that biases often guide the way, and may be directed by victim demeanour (Ask \& Granhag, 2005; Ask \& Landstrom, 2010; Bergelson, 2012; Bogoch, 2007; Bollingmo et al., 2009; Frohmann, 1991; Maier, 2008; 2014; Spears \& Spohn, 1997; Sussenbach et al., 2012; Wessel et al., 2012; Winkel \& Koppelaar, 1991). The way in which victims' testimonies are perceived by those in the criminal justice system is key, and can influence judgements of victim and evidence credibility. Thus, it is clear that research on the language used by emotional victims is essential. In the current study, we investigate the impact of figurative language, specifically hyperbole, on the perception of victim testimony.

\subsection{The Ideal Victim}

Research has shown how the emotions displayed by a victim can affect those who are listening for the purpose of recording statements or giving judgement. The general consensus is that jurors side with the victim who displayed emotions congruent to their distressed mental state, and have less sympathy and tolerance for those that were neutral or incongruent (Bollingmo et al., 2008; Kauffmann et al., 2003; Rose \& Nadler, 2002; Rose et al., 2006; Wessel et al., 2012; Winkel \& 
Koppelaar, 1991). This has been described by Ask and Landstrom (2010) as the 'emotional victim effect' which argues that the emotionality of a victim's demeanour influences perceived credibility. Due to the observer-expectation of the victim to behave in a specific manner, they often harbour definitive perceptions of what comprises 'normal reactions' for victims (termed 'normative victim demeanour expectancy'), especially those of sexual crime. If, for some reason, the victim fails to behave according to expectation, or causes an 'expectancy violation', it promptly causes suspicion, evokes negativity, and subsequently, causes victim credibility to plummet (Ask \& Landstrom, 2010; Bollingmo et al., 2008; Kaufmann et al., 2003; Matoesian, 2000; Winkel \& Koppelaar, 1991).

The emotional victim effect is a sexual crime-specific phenomenon of a much wider, and universally accepted concept of 'the ideal victim'. This was first highlighted in the seminal work of Nils Christie (1986) where he defined the ideal victim as "a person, or a category of individuals who - when hit by crime - most readily are given the complete and legitimate status of being a victim" (p. 18). The ideal victim has several extremely specific attributes which are contradictory at best and mutually exclusive at worst. They must be weak enough to be considered a victim, yet powerful enough to claim victim status. The offender must be unknown, and inherently 'evil', granting credibility to the victim who most ideally, must be engaged in an everyday chore, or a respectable project (Christie, 1986; Estrich, 1987; Larcombe, 2002; Stevenson, 2000; Van Wijk, 2013).

While originally termed and documented by Christie, the ideology is more than a few centuries old. Shakespeare's (1594) poem, The Rape of Lucrece provides the narrative of Lucrece, who was raped by a Roman prince, Tarquin. While the narrative takes a revengeful turn after Lucrece is raped, the characteristics and 
descriptions used by Shakespeare to provide the character with immediate victim status are congruent to those that are described by Christie almost four centuries later. Each characteristic essential to be perceived as the ideal victim, is present in Lucrece. While the other women around her, who are seen "dancing and revelling, or in several disports" (Shakespeare, 1594 as cited in Willbern, 1989, p. 182), Lucrece is found chastely spinning; hence observed as engaged in a 'respectable' everyday chore. Prince Tarquin primarily enters Lucrece's chamber that evening with the intention to seduce her. He is received politely, but when his apparent intentions become clear to Lucrece, he is met with resistance as Lucrece is married to another nobleman. His attempt at seduction fails even when he resorts to arguments consequently escalating to threats. As a final resort, he overpowers her, and rapes her. The narrative here depicts the meek demeanour expected of a woman (Frohman, 1991; Ponterotto, 2007; Stevenson, 2000) yet accompanied by the strong resilience of a rape victim (Christie, 1986; Estrich, 1987; Larcombe, 2002; Matoesian, 2001).

When Tarquin departs, Lucrece is left in "vigorous lamentation" (Willbern, 1989, p. 183) and consequently kills herself. Not only does the congruency of her emotions lead her to suicide, but the strength of these emotions is then acquired by her husband, who vows to avenge her rape and death. This is in some ways consistent with the claims of Rose et al. (2006) in that emotional consistency is essential for significant impact on secondary listeners. The characteristics of both the victim as well as the perpetrator are consistent with parameters described as essential by Christie (1986). Tarquin is firstly, an unknown intruder and subsequently an assailant. He is also resilient in that he inflicts physical harm while overpowering her. Conclusively, he is depicted consistently as 'evil' throughout the poem. This 
supports the concept of the ideal victim (Estrich, 1987; Larcombe, 2002; Stevenson, 2000) - and by virtue of this, the ideal perpetrator (Estrich, 1987) - which has been deeply embedded in the perception of sexual crime for several centuries, even within non-forensic literature.

The theory of the ideal victim has been revisited in recent literature, where these attributes are still essential in determining the credibility of a victim in the media (Van Wijk, 2013), and more importantly, in court (Maglione, 2016; Matoesian, 2001; Ponterotto, 2007; Spohn et al., 2001). Attributes have also been added: a victim's resistance must be overt, and injury must be sustained and documented (Estrich, 1987). Moreover, Stevenson (2000) lists the characteristics of valorised female victims as chaste, sensible, dependent, cautious, and responsible. The addition most relevant to this study was made by Larcombe (2002) "[The successful rape complainant] is not prone to exaggeration or embellishment but seems to talk straight. She answers questions quickly and precisely and speaks fairly and frankly without shame about sexual acts and activities" (p. 15).

From a sociological standpoint, the Affect Control Theory (Heise, 1987) states that strong congruent emotions of an individual in any given state of being provide information about how different their current state is from their fundamental state (Tsoudis, 2002; Tsoudis \& Smith-Loving, 1998); for example, in the case of a victim giving testimony, strong negative emotions would portray that the speaker has not consistently been a victim and is thus greatly impacted by the current situation. Conversely, in a victim with only mild negative emotions, listeners are more likely to perceive complacency in emotion-depiction, and the victim's fundamental state being close to their current state, requiring no strong evocations. Nadler and Rose (2002) also found that when victims maintained their congruent, emotionally upset 
behaviour from primary statements to the end of trial, the offender was more likely to be given a serious punishment as opposed to those who were upset and tearful at first, but calm and controlled later during the trial. Victim emotionality also strongly impacts legally admissible evidence. The United States law of evidence bars hearsay as admissible evidence with the exception (among others) of 'excited utterance'. An excited utterance is admissible assuming that it is impulsive, and beyond the agency and control of a speaker, hence a realistic evaluation of the situation as opposed to a calculated utterance with motive (Andrus, 2009; 2012).

Emotional cues, however, may or may not be intentional demonstrations (Leggitt \& Gibbs, 2000). While emotionality can be imperative in studying deception detection due to this very quality (Adams, 1996; Bollingmo et al., 2008; Ekman, $1993 ; 1997)$, it may not be as constructive in cases where innocence is the primary assumption. Verbal communication is a more robust form of conveyance in that speakers intend for their listeners to perceive and recognise, and cause thought or action (Grice, 1957). Despite this, none of these studies have considered the impact of the language used by the victim.

\subsection{Language in Forensic Settings}

Verbal cues of a victim are especially important where the basis of establishing the credibility of a victim-witness is weak; often without any additional witness or evidence besides the alleged suspect and victim themselves (Ask \& Landstrom, 2010; Baldry \& Winkle, 1998; Coates et al., 1994; Danet, 1980; Maier, 2014). Verbal cues help provide insight into a victim's state of mind during the incident, and the nature of acquaintance with their perpetrator (Coates et al., 1994) among other factors - both of which have been stated as indicators of the 'ideal victim' measures (Ehrlich, 2007). However, there are anomalies in analysing verbal 
behaviour in court. According to the Birmingham Model of Discourse Structure (Sinclair \& Coulthard, 1975) a spontaneous conversation consists of a series of three-part exchanges: question, answer, and follow-up. For example:

Question: What time do we leave for the bus?

Answer: About 4 p.m. I think

Follow-up: Oh, okay.

This structure is usually followed, and is also characterised by hedging and overlapping. Courtroom dialogue, however, is "highly structured, and lacks characteristics of spontaneous conversation" (Ponterotto, 2007, p. 111) and thus occurs predominantly in two parts: questions and answers. The delivery of the follow-up is eliminated along with the freedom to hedge or overlap. Moreover, answers are often limited to yes or no alternatives, providing the victim with extremely limited discursive space (Larcombe, 2002; Young, 1998); also termed the 'discursive trap of rape trial protocol' (Ponterotto, 2007). This would imply that primary victim statements - having none of the discursive limitations of courtroom dialogue - become all the more important, giving the victim discursive freedom to describe their experience without the certainty of leading questions.

This study focuses on a specific feature of linguistic communication: figurative language. Figures of speech are commonly used in both, colloquial and formal language (Cano Mora, 2009; Kreuz \& Roberts, 1995; Roberts \& Kreuz, 1994), however, there is no research to our knowledge which examines their impact in the legal sphere. There is a large volume of literature on victim-impact statements, which are statements provided in court by friends and family of the victim, describing the impact of the crime on their daily lives (Bandes, 2017). These statements are rarely provided by the victim themselves and are yet touted as an empathic narrative with 
the power to sway sentencing (Bandes, 2017; Hills \& Thompson, 1999; Nadler \& Rose, 2002). There is, however, almost no literature on primary victim statements (Maier, 2014). When the combination, nature, and intensity of words are given such strong relevance, it becomes crucially important to pick up on each type of speech and analyse the effect it might or might not have on those listening.

\subsection{Hyperbole and its place in Rhetoric and Psycholinguistics Literature}

Different types of figurative language have been assigned discourse goals, implying that they have a specific function in a certain scenario making them preferable over their literal, nonfigurative counterpart. Within psycholinguistics, eight prevalent types of figurative language exist. These are: hyperbole, idiom, indirect request, irony, understatement, metaphor, rhetorical question, and simile (Roberts \& Kreuz, 1994). The hyperbole as a figure of speech (e.g., "I've been waiting ages"; "my bag weighs a ton"; "this room is hotter than the sun"; "that lecture bored me to death") can be defined as an expression which "exceeds the (credible) limits of fact in a given context" (Claridge, 2010, p.5). It has also been defined as "an expression that is more extreme than justified, given its ontological referent." (Burgers et al., 2016, p.163). Most definitions emphasize the key elements of hyperbole with exaggeration (Carston \& Wearing, 2015), overstatements (Colston \& Keller, 1998), excess (Cano Mora, 2004; 2009) and extremes (Norrick, 2004). Taking numerous facets into account, Carston and Wearing (2015) describe hyperbole as "a trope which involves deliberate and overt exaggeration (along a particular scale), it is flexible with regard to how it can be expressed (allowing for degrees of exaggeration) and it is capable of combining with a range of other tropes." (pp. 81). This will be the operational definition used for this study. 
Hyperbole has classically been studied within the field of rhetoric, and is associated with persuasive and powerful speech (Cano Mora, 2009; McCarthy \& Carter, 2004). Literature on metaphor and irony provides useful insights into the functions and perceptions of hyperbole where the discourse goals are humour, clarification, or emphasis (Kreuz \& Glucksberg, 1989; Kreuz \& Roberts 1995; Roberts \& Kreuz, 1994). Studies find that when used in the realm of evaluation, hyperbole is most commonly used in negative evaluations of situations, as opposed to positive (Anderson \& Leaper, 1998; Cano Mora, 2009; Claridge, 2010). This refers to the high occurrence of hyperbole in describing situations involving chaos, pungency, evil, frightfulness, violence, destruction, sorrow, and loss of control as opposed to when describing perfection, magnificence, splendour, or beauty (Cano Mora, 2009). It is essential to note here the Pollyanna Hypothesis (Boucher \& Osgood, 1969), which is the linguistic principle parallel to the Affect Control theory (Heise, 1987). The Pollyanna Hypothesis comments on the likelihood of humans to consider negative situations as more noteworthy, hence reported in a more descriptive way when compared to positive situations. To draw a parallel in simple words, negative situations are usually described with grander adjectives or phrases that specifically convey that they are not the norm. This creates necessity (as well as a rationalisation) for the very 'embellishment' that Larcombe (2002) warns the complainant against.

Out of the variety of characteristics of hyperbole essential for pragmatic studies, two emerge as fundamental. The first is seemingly overt in that it applies to most communication: hyperbole is incomplete without a listener paradigm (Carston \& Wearing, 2015; Leggitt \& Gibbs, 2000). This proves essential because the current study primarily tests how this listener perceives a hyperbolic victim. The second 
suggesting that hyperbole is unidentifiable, unless in context (Burgers et al., 2016; Carter \& McCarthy, 1997). This is essential because this study aims to investigate whether the affective context makes a hyperbole more, or less credible.

Kreuz and Roberts (1995) identify another fundamental characteristic of the hyperbole which they term 'nonveridicality' which is "a discrepancy in utterance and reality" (McCarthy \& Carter, 2004). The implications of nonveridicality when studied from the angle of victim perception could be imperative in that the discrepancy could be taken as a lie along with several violations of the Gricean maxims. With the legal sphere recently making pathways for laws such as the victim-liability law, the subconscious perception of an exaggeration as a discrepancy or a lie by a deciding authority, could immediately mean a variance in verdict. In an environment where victims are generally perceived as undeniably innocent and correct, victim liability introduces the concept of building a defence based on victim wrongs (Bogoch, 2007; Ehrlich, 2001; Frohman, 1991) which is highly controversial - especially when dealing with sexual offences - but is also now being deemed decisive (Gruber, 2003).

A contradictory idea is that a hyperbole is exempt from being a lie by virtue of there being a common ground of pretence between a speaker and his or her listener/s, and is distinguished from a lie in its inherent nature of being overt and open to recognition (McCarthy \& Carter, 2004). Nair (1985; see also: Nemesi, 2010) adds to Grice's maxims by pointing out that unlike a lie, hyperbole is viewed as socially acceptable and the two are hence, different. However, because the hyperbole is only legitimised in social interaction (Carston \& wearing, 2015; Carter \& McCarthy, 1997; Leggitt \& Gibbs, 2000), and is not the sole function of a speaker, its perception as either deceptive or overt is incomplete without including the paradigm 
of a listener. It is of interest to this study to holistically examine this interaction between the affective speaker and his or her listener.

Non-corpus-based literature overtly about the perception of hyperbole is largely absent (Cano Mora, 2004; Claridge, 2010). Hyperbole, however, has been studied in the psycholinguistics and rhetoric literature as an extension of irony and metaphor respectively; these insights might provide an indication of hyperbolic perception. Leggitt and Gibbs (2000) investigated the perception of, and reaction to, verbal irony. They recruited undergraduate students and provided them with 28 short stories presented as a short conversation between two individuals; each of which ended with one kind of ironic statement. The two that are relevant to this study were the ironic overstatement and the ironic understatement. At the end of each scenario, participants were asked to rate their current emotions on a 7-point scale with options ranging from 'merry, joyous' to 'disgusted'. Participants were further instructed to empathise with the person that the ironic statement was directed towards and base their emotional state on this personalisation. It was found that overstatements immediately evoked negative feelings and resentment towards the speaker due to their nature of magnifying problems that may not necessarily deserve magnification. Even though participants perceived the speaker's intention as non-threatening and positive, the feelings evoked due to this speaker's overstatement were quite the contrary. While an overstatement is only one type of hyperbole, Leggitt and Gibbs were successful in establishing the importance of the listener's perception in a social interaction involving figures of speech. This elicits serious consequence for an affective speaker whose listener is a legal authority.

An inference can thus be made that if the authoritative listener is inherently and already sympathetic to a victim's situation prior to a statement, the speaker will 
be met with sympathy. However, should the listener not regard the victim's situation as distressing or even serious, a hyperbolic victim statement will evoke at least negative feelings, if not complete dismissal by a listener (Claridge, 2010). Literature within forensic psychology (Ask \& Granhag, 2005; Baldry \& Winkel, 1998; Bollingmo et al., 2008; Bollingmo et al., 2009; Kaufmann et al., 2003; Memon et al., 2003; Rose et al., 2006; Winkel \& Koppelaar, 1991) stresses the benefits of being a consistent victim, nonetheless, the question remains whether the consistency in the hyperbole in a victim statement merely functions to subsequently evoke negative feelings. This study aims to apply the emotional congruency theories of Rose et al. (2006) to the forensic linguistics paradigm to investigate the role of hyperbole in victim statements, and more importantly, study its consequences.

\subsection{Current study and predictions}

In the current study, two experiments are conducted using two different participant pools: a specialist population who have experience with, or knowledge of victim statements (Experiment 1) and participants from the general population who do not have any specialty in forensics or victim support, but would be eligible to serve on a jury (Experiment 2). Experiments 1 and 2 are otherwise identical. There will be 16 written scenarios which are presented as a conversation between an authority figure and a complainant. Each scenario contains a number of statements that are presented in either a hyperbolic or non-hyperbolic version. Participants will be asked to read these scenarios and after each scenario, answer four close-ended questions pertaining to four separate measures of perception - belief, sympathy, victim-impact, and likability, and an open-ended question, asking participants to provide reasoning for their choices. 
A purely forensic perspective (Christie, 1986; Estrich, 1987; Larcombe, 2002; Matoesian, 2001; Rose et al., 2006) would suggest that hyperbole will make a victim seem more impacted and believable, hence increase the sympathy felt by participants towards the complainant. A linguistic perspective (Cano Mora, 2009; Claridge, 2010) would suggest that while hyperbole (in theory) functions to emphasise emotions, its perception is empirically negative when a listener is added to the equation. This in turn, should cause sympathy and believability to be reduced. Linguistic literature however, also dictates that hyperbole is unwelcome where undeserving situations are magnified (Leggitt \& Gibbs, 2000; McCarthy \& Carter, 2004). Quintilian (1921) goes so far as to warn speakers from being too affective or hyperbolic as exaggeration only deserves to be used when the magnitude of the situation goes beyond words; in such circumstances he claims, that hyperbole will be more effective than literal language (Nemesi, 2010). While 'undeserving' situations may be plenty in number in normal conversation (talking about how hot a room is, or how long you had to wait for someone), it might be safe to assume sexual crime as a 'deserving' situation. It would be interesting to empirically examine the effects of hyperbole on a deserving narrative with both fields taken into consideration.

\section{Method}

\subsection{Participants}

2.1.1 Experiment 1. There were 32 participants (11 male, 21 female, mean age 35.75). All participants were from one of three categories: social workers currently working or volunteering within organisations that provide victim aid $(N=13)$, law enforcement officers $(N=6)$, and students of forensic psychology/forensic mental health/forensic science $(N=13)$. These participants were targeted since they tend to 
be (or are in training to be) the primary judges of victim credibility, and are most likely to be approached by a victim wishing to report an assault or provide a statement. Professional participants were recruited through emails to the point of contact in each organisation, the vast majority of which were charities operating to offer support to victims of sexual crime. Student participants were recruited through emails to their university account either directly from the researcher, or the module convenor. Participants were entered in a prize draw to win one of two $£ 20$ Amazon vouchers.

2.1.2. Experiment 2: There were 32 participants (12 male, 19 female, 1 preferred not to say, mean age 40.75). All participants were from the general public, were native English speakers, over the age of 18 , and eligible for jury duty. Participants in this group were recruited through social media postings on Facebook, and through survey-participation websites such as SurveyCircle and SurveyTandem. Participants from this group were also entered into a prize draw for $£ 20$ Amazon vouchers. This group was targeted to provide a contrast (if any) in results from the professionals.

\subsection{Materials and design}

Participants in both experiments were presented with 16 written scenarios. Each scenario depicted a fabricated conversation between an alleged victim of a sexual crime, and a criminal justice authority (such as a law enforcement officer or a lawyer) and occurred in a legally relevant setting (such as a police station or a courtroom). The statements were $250-300$ words long, and described a victim's experience with either rape, sexual assault, or sexual harassment. Each statement contained phrases which were either hyperbolic (e.g. "I used to think I was the luckiest boy in the world"), or non-hyperbolic (e.g. "I used to think I was a very lucky boy") in nature. An example scenario is presented (hyperbolic and control phrases 
are in bold; the first phrase was viewed in the hyperbolic condition, the second in the control):

Complainant $B$ is a 19 year old female alleging sexual assault. The following is an extract from a hypothetical conversation between the complainant and a police authority. Please read this carefully, and then answer the questions that follow. Complainant B: "Can I report an assault?"

Police Officer: "Please begin by telling us what happened and where."

Complainant B: “I'm a student. I was walking back home from the university and I lost my presence of mind for just a second/for a bit. I decided to take the shortcut through a car park on my way. It was $8: 23 p m$, I thought l'd be okay but I didn't... didn't know it only took no time/a little time for my world to end. I had a bag, so I think I hit him, but it came faster than I could blink/very quickly. Like, he was behind me, put an arm around my neck, and began to choke me. He then put his fingers down my skirt, then tights...l could feel myself disintegrating in his hands/giving up, and then tried to take them off, but he couldn't. At some moment in that eternity/time, I think he had his...uh, his... bloody monster fingers/fingers inside me. I can't be sure. Blue backpack, black jeans. He then ran away. I don't know anything. I don't know anything, literally nothing/l don't know enough. I can't remember enough, really. I'm not even being helpful, am I? I make zero sense/l don't make much sense. Does this make sense?"

After reading each scenario, participants answered seven questions. The first four questions were on a five-point yes/no scale ranging -2 (No) to 2 (Yes). These questions addressed believability (Do you believe the complainant?), sympathy (Do 
you sympathise with the complainant?), impact (Do you believe that the complainant has been impacted by the crime against them?) and likability (Do you like the complainant?). The quantitative questions were followed by a single open-ended question asking participants to justify their answers in the previous question of belief (What made you believe/disbelieve the complainant?).

The study was a within-subjects design and participants saw eight scenarios containing hyperbole and eight without. Specifically, scenarios were counterbalanced across two different versions of the questionnaire such that participants saw 16 scenarios in total, however only saw each scenario in either its hyperbolic version, or its non-hyperbolic version.

2.2.1 Linguistic Considerations. There were seven to nine hyperbolic (or control) phrases per scenario; each scenario had a mix of single word hyperboles (e.g., everything, nothing, literally, endless), phrasal hyperbole (e.g., faster than I could blink) and clausal hyperbole (such as repetition of phrases and/or pre-modifiers for certain words). Across all scenarios, hyperbole from each of the above subcategories, along with varieties from all three domains of hyperbole were employed; the three domains being: realistic hyperbole, possible but improbable hyperbole, and impossible hyperbole (Colston \& Keller, 1998). Phrases were controlled for length across hyperbolic $(M=24)$ and non-hyperbolic conditions $(M=$ 22.7) with regards to number of words $t(30)=.460 ; p=.649$. It is important to note that control phrases were not always literal. They contained no hyperbole, however, no restriction was made with regards to other types of figurative language.

2.2.2 Forensic Considerations. The nature, speech, and reactions within victim statements were all written to be in accordance with normative victim demeanour expectancy. That is, males were presented as more aggressive and resentful, used 
stronger language, and provided more linear narratives. Females in turn were inclined towards shame, remorse, and self-blame, and provided less linear but more emotional narratives (Bollingmo et al., 2009; Kaufmann et al., 2003; Rose et al., 2006). The only principle of normative victim demeanour expectancy not followed was that of compliance; regardless of sex, victims were equally compliant or posed strong resistance.

The scenarios also balanced nature of familiarity between the victim and the perpetrator (equal number of known vs. unknown assailants), sex of the victims (equal number of male vs. female victims), along with the nature of sexual crime (equal number of incidents with sexual harassment vs. sexual assault). Sexual assault scenarios were further divided into penetrative assault (rape) and nonpenetrative assault, which were also equally balanced.

\subsection{Procedure}

Participants were informed that they were taking part in an online survey investigating the credibility of victim testimony. They were invited using a link. They completed the survey using Qualtrics, online from their own devices. Upon clicking the link, participants were presented with an information sheet detailing the purpose, nature, and contents of the study. They signed a consent form agreeing to participate in the study along with a GDPR statement which they must also consent to, in order to progress. They then filled in demographic details: age-range and gender for both Experiments 1 and 2, with an added section for occupation in Experiment 1. Their email addresses were recorded on the next page, however, this was optional and collected only to contact the winner of the prize draw after which any identifying information was deleted. They were then presented with the questionnaire where they read 16 scenarios which were each followed by seven 
questions. This procedure was repeated 16 times until they had read eight hyperbolic and eight non-hyperbolic scenarios (presented in a random order), and answered questions after each.

To alleviate any emotional distress, following the 16 scenarios, participants engaged in questions requiring them to select their preferences of cute animals. At the end of the survey, they were presented with a participant debrief form. The debrief gave further information about the rationale of the study, informing participants about the hypothesised link between hyperbole and victim perception.

\section{Results}

Paired-samples $t$-tests were performed by calculating mean values from data that was averaged across both participants ( $t 1)$ and scenarios ( $t 2)$ (in order to take both subject and item variation into account) to explore the effect of condition (hyperbole/no hyperbole) on each of the four counts of credible perception - belief, sympathy, victim-impact, and likability. Cohen's $d$ was calculated as a measure of effect size.

\subsection{Experiment 1}

3.1.1 Belief. Participants were asked to rate whether they believed the complainant's statement on a scale of -2 (No) to 2 (Yes). There was a significant difference in the means of scores calculated by participant $t 1(31)=3.5, d=1.0, p=$ .001 and by scenario $t 2(15)=5.8, d=1.4, p<.001$. This suggests that victim statements were significantly more believable when they were non-hyperbolic, than when hyperbole was used (see Figure 1). 


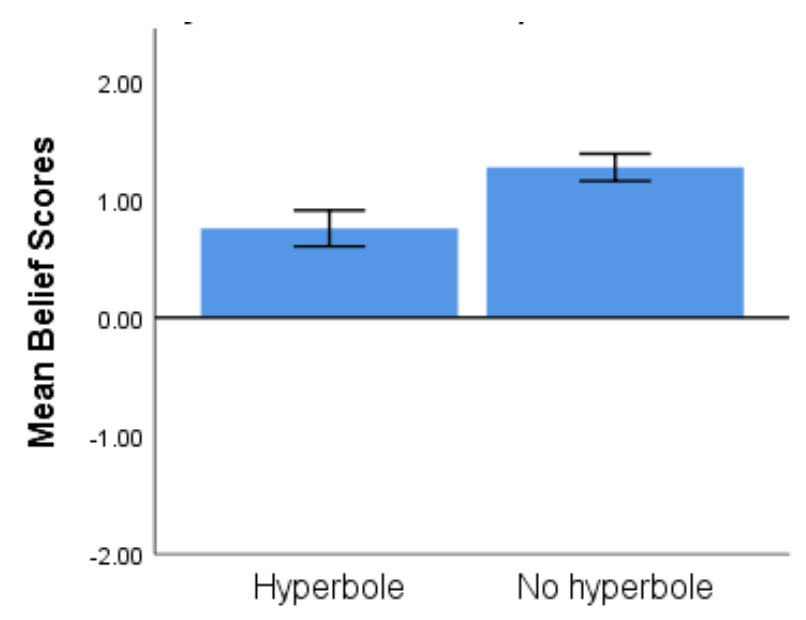

Figure 1. Mean belief scores with standard error of participants in the hyperbolic and non-hyperbolic conditions.

3.1.2 Sympathy. Participants were asked to rate whether they sympathised with the complainant based on the victim-statement on a scale of -2 (No) to 2 (Yes). There was a significant difference in the means of scores calculated by participant $t 1(31)=3.6, d=.9, p=.001$ and by scenario $t 2(15)=3.8, d=1.0, p=.002$. This suggests that victim statements were significantly more sympathised with when they were non-hyperbolic than when hyperbole was used (see Figure 2).

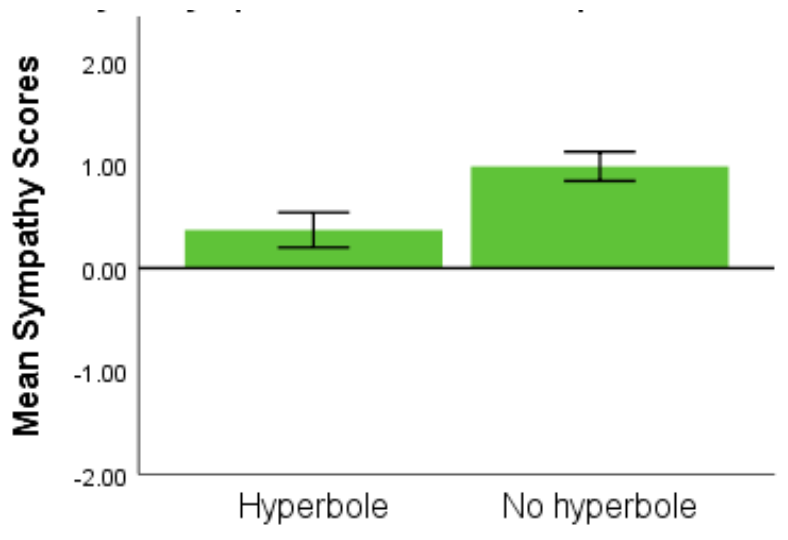

Figure 2. Mean sympathy scores with standard error of participants in hyperbolic and non-hyperbolic conditions

3.1.3 Victim-impact. Participants were asked to rate whether they believed the complainant was impacted by the crime based on the victim-statement on a scale of -2 (No) to 2 (Yes). There was a significant difference in the means of scores calculated by participant $t 1(31)=2.7, d=.6, p=.01$ and by scenario $t 2(15)=3.4, d=$ 
$.7, p=.004$. This suggests that victims seemed significantly more impacted when statements were non-hyperbolic, than when hyperbole was used (see Figure 3).

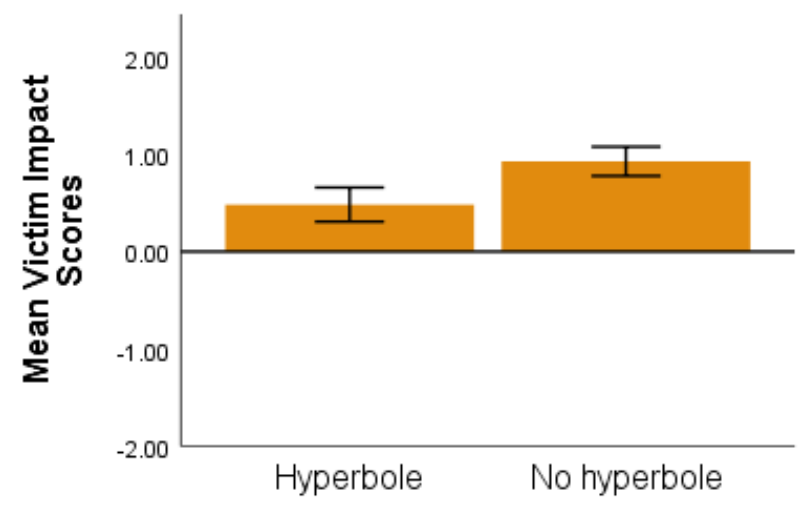

Figure 3. Mean victim-impact scores with standard error of participants in hyperbolic and non-hyperbolic conditions

3.1.4 Likability. Participants were asked to rate whether they liked the complainant based on the victim-statement on a scale of -2 (No) to 2 (Yes). There was a significant difference in scores calculated by participant $t 1(31)=3.4, d=.9, p$ $=.002$ and by scenario $t 2(15)=4.4, d=1.3, p=.001$. This suggests that the complainants were significantly more likeable when their statements were nonhyperbolic, than when hyperbole was used (see Figure 4).

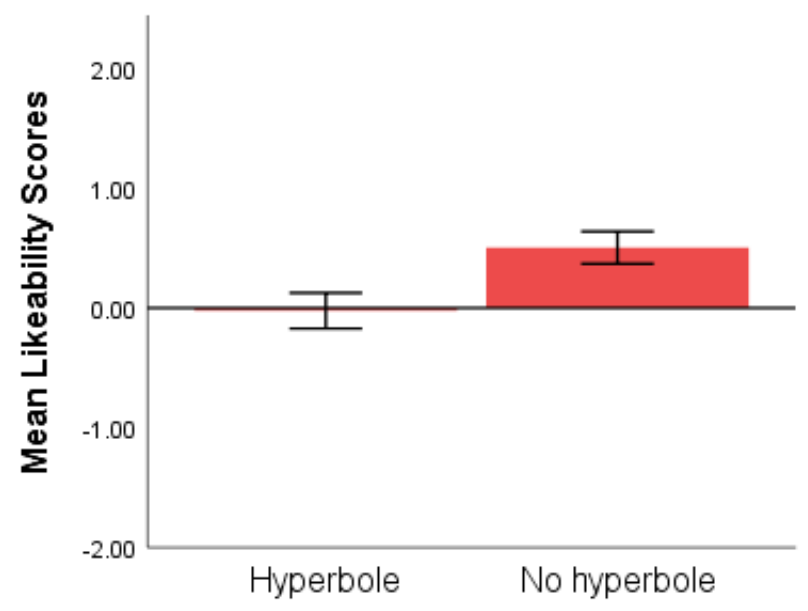

Figure 4. Mean likability scores with standard error of participants in hyperbolic and non-hyperbolic conditions

Results from the qualitative question revealed participants' motives behind believing or disbelieving the statements that they read. The following statements 
made by participants are provided to illustrate the direction of the quantitative findings. They are segregated into hyperbolic and non-hyperbolic, based on the condition that the participant viewed the specific scenario in.

Hyperbolic condition. "There is something very verbose and poetic about the way the complainant recalls the events. I wouldn't base a sentence on it. But it doesn't seem like the complainant is recalling from a state of distress, rather it seems rehearsed; which due to how heinous the nature of the crime in question is, doesn't seem necessary."

"He seems disturbed, but he's extremely rude! If it happened that long ago, he should've learnt some composure by now, seems like it happened yesterday." "Sounds somewhat dramatic, but the jumbled sentences could be explained as a result of perceived shock."

"You can see the emotional impact of the incident on her mind. Quite apologetic also shows she possibly blames herself."

"I feel they have exaggerated. It may have been going on for 3 years but how strongly they feel about it i feel that it's only been a fleeting comment"

Non-hyperbolic condition. "The emotional language used and the defensive language to being not believed, made me believe the complainant" "I cannot imagine someone lying about something like this, and it makes sense that if he has been experiencing abuse since early on that he might have thought that was normal to some extent. However the way he gave his statements is a little sketchy, which makes me thing [think] he may be exaggerating."

"The level of detail originally given before an obvious uncomfortability [discomfort] about having to go into more detail made me believe the complainant." 
"There was a lot of ambiguity and she seems unsure about everything that happened which made me believe her less. Also it is a strange incident that I have not heard of happening before which also made it less believable for me"

\subsection{Experiment 2}

The analysis procedure was identical to that used in Experiment 1.

3.2.1 Belief. The main effect of believability was significant in the analysis by participants, $t 1(31)=2.2, d=.8, p=.03$, but not by scenarios, $t 2(15)=1.4, p=.2$. This suggests that contrary to Experiment 1, there is some evidence that complainants were more believed when their statements were hyperbolic than when no hyperbole was used (see Figure 5).

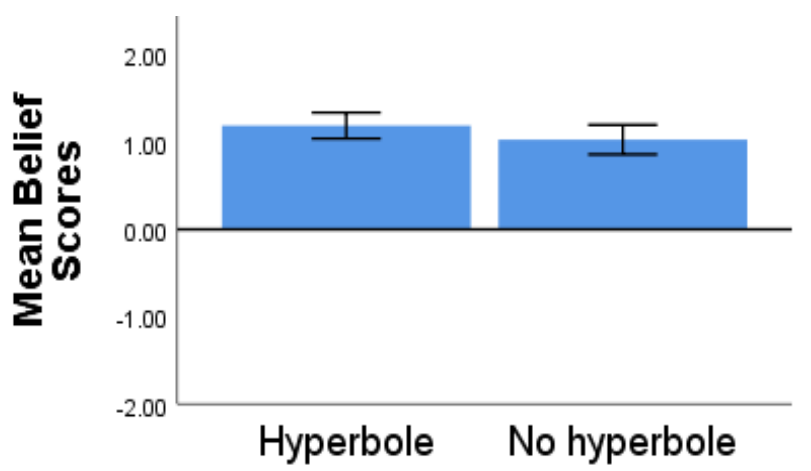

Figure 5. Mean belief scores of participants in the hyperbolic and non-hyperbolic conditions.

3.2.2 Victim Impact. There was a significant difference between hyperbolic and non-hyperbolic conditions $t 1(31)=2.6, d=.2, p=.01, t 2(15)=2.2, d=.2, p=.04$. This suggests that contrary to Experiment 1, complainants were thought to be significantly more impacted when their statements were hyperbolic than when no hyperbole was used (see Figure 6). 


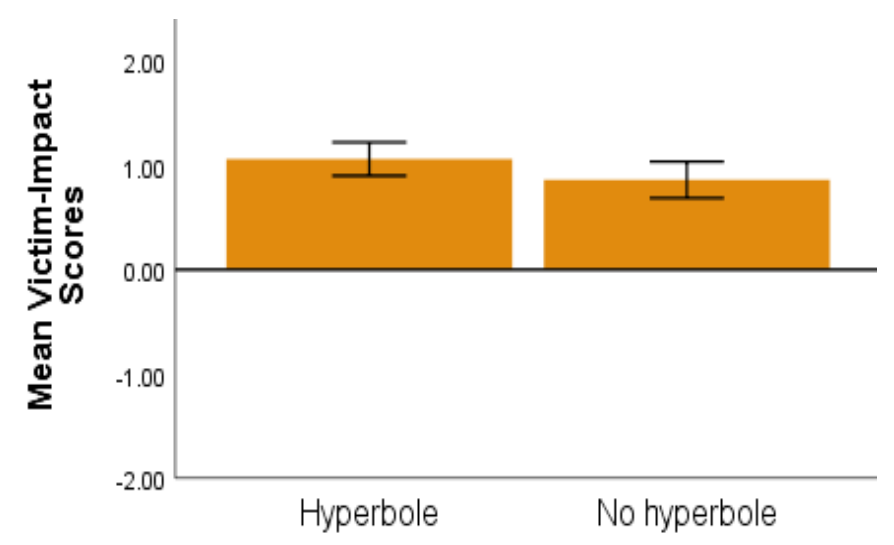

Figure 6. Mean victim-impact scores and standard errors of participants in hyperbolic and non-hyperbolic conditions

3.2.3 Sympathy. No significant differences were found between hyperbolic $($ Mean $=1.1, S E=.1)$ and non-hyperbolic $($ Mean $=1.0, S E=.1)$ conditions; either when calculated by participant $t 1(31)=1.2, p=.2$ or by scenario $t 2(15)=.9, p=.4$.

3.2.4 Likeability. No significant differences were found between hyperbolic $($ Mean $=.4, S E=.1)$ and non-hyperbolic $($ Mean $=.4, S E=.1)$ conditions; either when calculated by participant $t 1(31)=1.2, p=.2$ or by scenario $t 2(15)=.2, p=.9$.

Results from the qualitative question revealed participants' motives behind believing or disbelieving the statements that they read. The following statements made by participants are provided to illustrate the direction of quantitative findings. They are segregated into hyperbolic and non-hyperbolic, based on the condition that the participant viewed the specific scenario in.

Hyperbolic condition. "I don't believe due to the descriptive nature of the language used i.e. lost my presence of mind I was broken in spirit” "The uncontrolled outbursts at the end made it especially believable" "Believe, statement reads of frustration in the tone, accused's character not fitting with actions. She has made it more believable by pointing out contrasting factors, rather than all one sided There is a lack of specificity for detail about actual events, apart from the quote, but the comment 'its got to stop' suggests reaching a breaking 
point. The last part seems emotionally charged, which suggests its of the cuff and therefore more likely factual."

"the statement sounds quite dramatic and emotive, in a way making it less believable"

"Victim seemed quite emotionally invested, not really any reason to make this complaint if it wasn't true"

"He seems very aware that what's been done to him was wrong. That almost makes it more believable. Hes also not changing his manner of speech. It seems natural.”

Non-hyperbolic condition. "Her bravery and honest account really shines through in this section. Especially after the defence's disrespectful replies"

"Believe. Saying she feels she might have deserved this, questioning her actions contributed, her choice of words suggests rather low self esteem, which fits with a delayed reporting. Link that with the fact she asked "can i report a rape" as if the answer might be "no". Blaming herself for not taking advice from friends fits the same characterisation. Theres consistency to wording for being a victim, almost apologetic for reporting. That consistency of tone doesnt ring of someone making strong accusations based on a lie."

"He steps through that explanation using a reasonable tone, with consistency. His statements build the story in steps and dont contradict. Nothing he says seems out of place or counter to the central tenet of being placed in an bad situation, and feeling out of place. "I'm scared", "I was struggling" stand out as being victim statements, not bold or forceful, it fits the claim of being taken advantage of by a power differential and abused. He was looking to those in a more superior position than him to say "cut", thus consistently describing he was deferential and vulnerable." 
"She indicates a lot of self-destructive tendencies, seems to live on survival instinct from moment to moment, that nature might be indicative of lying. But she is not trying to hide aspects of her character which you think might negatively impact accepting the validity. By being open and potentially honest about what she says she has done in the past, adds credibility to believing the rest of the statement. She talks like she's tough, but admits she cried for days. By providing a direct and balanced account of her experience, it suggests she is speaking truthfully."

“Very vague, didn't seem very affected by the alleged crime and didn't seem very emotional"

\section{Discussion}

The aim of the current study was to investigate the impact of hyperbole on the perception of victim testimonies. There were a number of key findings. In Experiment 1 , hyperbole in victim statements had an overall negative effect on all four tested measures of victim perception: belief, sympathy, victim-impact as well as likability. In contrast, in Experiment 2, hyperbole had a positive effect on two out of the four tested measures: belief and victim impact. It had no impact on the measures of sympathy and likability.

\subsection{Comparisons with evidence from rhetoric literature and psycholinguistics}

These findings are consistent with the linguistics literature on a number of levels. First and foremost, they support the primary claim that figurative language is incomplete without a listener paradigm (Cano Mora, 2004; 2009; Carter \& McCarthy, 1997; Leggitt \& Gibbs, 2000; McCarthy \& Carter, 2004). This consequently evokes the question of how a listener perceives figurative language, which leads to consistency with Leggitt and Gibbs' (2000) second claim, of hyperbole evoking negative feelings. As in Leggitt and Gibbs' experiment, Experiment 1 reported here 
also had participants perceive the victims' intentions as positive and non-threatening - participants' answers to qualitative questions repeatedly revealed comments that implied that the victim's situation and victim status deserved sympathy. Thus, the complainants' language elicited evocations of sympathy from participants in general, however, the use of hyperbole nevertheless evoked less positive ratings from participants.

There are two essential differences between the method used by Leggitt and Gibbs (2000), and the one used in this study. First, the former instructed participants to assume the position of the primary listener (i.e., assume the statements were directed towards the participant themselves) whereas in the current study, participants remained secondary listeners. Second, Leggit and Gibbs (2000) did not treat hyperbole as a separate trope. The reactions they observed were to the ironic understatement and ironic overstatement as opposed to the absence of deliberate irony in this study. Despite this major difference, the results found by both remain the same. Specifically, it can be inferred that the negativity evoked by a hyperbolic statement permeates the primary listener, and evokes negative feelings even in a secondary listener whom the statement was not directed towards. Further, the negativity of the hyperbole does not solely arise from the tropes that it co-occurs with; it has a negative effect of its own.

In Experiment 2, however, hyperbole performed more in line with its rhetoric expectations. Analysis of the findings from Experiment 2 indicates that the nonspecialist group of participants, though not directed to assume the position of the primary listener, may have done so, and accepted the hyperbole as a necessary tool to convey the complainant's affect. One participant went so far as to describe their own story of sexual assault: "Believe her cause it is not easy coming forth, and even 
if he knew it was wrong then, sometimes people don't listen or take you seriously, I was not took seriously in 1992, they kept trying to connect it to a second attack in which the man was stopped and I tried to tell them what put me in that condition to begin with". The positive impact of hyperbole on the measures of belief and victimimpact suggests that non-specialist participants had a higher emotional involvement towards both, the crime and the statement from the complainant.

The interpretation of these results forces a comparison between the perception of hyperbole and that of other types of figurative language. Research data on the function of sarcasm, for example, demonstrate that in certain situations, it is perceived as humorous and less insulting than a literal criticism, whereas in others, as being incredibly harsh (see e.g., Bowes \& Katz, 2011; Boylan \& Katz, 2013; Filik et al., 2016; Kreuz \& Glucksberg, 1989; Kreuz \& Roberts 1995; Leggitt \& Gibbs, 2000; McCarthy \& Carter, 2004; Pickering, Thompson, \& Filik, 2018; Roberts \& Kreuz, 1994). Roberts and Kreuz (1994) note that information about the type of figurative language to use in a specific situation is provided metacognitively to a speaker; this means that the speaker who uses figurative language perceives its function by gaining information from language itself. However, considering the interactive nature of figurative language, it is impossible to determine whether the listener perceives this function in a manner identical to that of the speaker. For example, in a scenario where a complainant uses hyperbole with the intent to emphasise trauma and pain, one specialist participant observed the hyperbole coming across as sarcasm ("I believe him, but some of his speech just sounds sarcastic."). In another scenario, specialist participants perceived the complainant to be "dramatic" and "entitled" in the hyperbolic condition as opposed to genuinely impacted. Hyperbole, as discussed previously, has three main discourse functions: 
impact, emphasis and finally, humour. It is clear from the qualitative statements that the participants who are the listeners, often assume a different function than the one intended by the speaker. In certain scenarios, the hyperbole functions to convey the intended connotation of impact: "He seems very dramatic, but also extremely shocked...and he explains his emotions and it's understandable why he would be shocked"; however in other scenarios, it is perceived as either sarcastic, doctored and rehearsed, or entirely fabricated: "[...] But it doesn't seem like the complainant is recalling from a state of distress, rather it seems rehearsed; which due to how heinous the nature of the crime in question is, doesn't seem necessary."

In Experiment 2 however, non-specialist participants have not only been successful in identifying the exaggerations, but they have also been able to assign a discourse goal identical to that of their speaker:

“Worded like, 'world to end', 'broken in spirit', makes it seem a bit overdramatised. However, still being in after shock of the incident could impact the retelling."

This primary difference between the perceptions of specialist and nonspecialist participants can be explained if we look at the scenarios while making considerations for professional differences. To a large extent, the law exclusively allows for a binary narrative; be it dichotomous answers expected of victimwitnesses (Bogoch, 2007; Ponterotto, 2007) or fractal recursivity (Andrus, 2009; $2011 ; 2012)$. Andrus (2012) expressly speaks of the binary nature of the excited utterance-exception to the US law of evidence on hearsay. Paramount to this exception is the state in which it was uttered; an excited utterance must be uttered in a state of distress, in a situation 'worthy' of causing excitement or nervousness. The excited utterance is admissible assuming it unequivocally true by virtue of impulsivity 
and a lack of agency on part of the speaker (Andrus, 2009); by default, rendering other reflectives - that may arise following further thought_false, or at least untrustworthy. Considering the legal gravity allotted to impulsive emotions and utterances, it seems plausible that hyperbolic or affective language when used in scenarios where complainants do not immediately speak in the aftermath, may seem unnecessary, or even manipulative to specialist participants.

Moreover, while the specialist participants may view these scenarios as a product of their workplace, non-specialist participants may view it as a one-to-one conversation with an affective individual who simply has chosen to convey their emotion (Claridge, 2010; Gibbs, 1994; Pollio \& Barlow, 1975). This can be viewed in two different manners: either non-specialist participants tend to perceive more effectively the fine nuances of emotion as opposed to the specialists, or, nonspecialists are quicker prey to affect and emotion and would lack the expertise required to weed out deception—when required—compared to specialist participants. This may seem like an obvious observation but it is also an important one; while specialist participants are more likely to fulfil tasks such as providing mental health help to victims and providing testimonies in court, it is the nonspecialist participants who constitute a jury that decides the fate of a perpetrator at trial.

\subsection{Comparisons with evidence from forensic psychology}

Rose et al. (2006; see also Kaufmann et al., 2003) found similar results while conducting experiments to test how a victim's emotions were perceived by observers. They found that although victims were expected to behave in a certain way, there was no certainty on what made an emotional response acceptable or normal. Strong displays of emotion were beneficial but it was found that this rule was 
conditional - males were expected to have as severe an emotional reaction as females, but for a shorter period of time; males in authoritative positions were expected to display anger and aggression as opposed to sadness or remorse, which was more suitable when displayed by females. It is important to note that although Rose et al. (2006) researched observers' reactions to different emotions displayed by victims, a close study of their experiment reveals that their scenarios written with the intention to display severe emotion included hyperbolic statements, for example, "What happened is on my mind from the time I wake up in the morning until I go to bed at night. I get bent out of shape over any little thing, and it seems like I'm always feeling down." (p. 208) and ones written without this intention, did not. In addition, sentences written with the intention of strong emotional portrayals were either wittingly, or unwittingly by the researchers, written including more varieties of figurative speech such as metaphor and simile along with the obvious hyperbole. Participants were also tested on whether the victim had 'likeability', and it was found that although mild emotional reactions were considered unusual and decreased credibility, it was the 'stoic', calm and controlled victim that was liked and preferred by observers. The results from Experiment 1 display a similar trend within participants who believed the victims to be highly impacted in the control condition, due to their strong emotional depictions, however, penalised the same evocations when accompanied by fitting language. They tended to more positively perceive the statements of those who spoke logically versus those that tended to use emotional exaggerations. An inference can be made that it was not the affect that has been penalised, but the dramatic language used to describe these events. There is a strong disconnection between an observer/listener's concept of a credible victim, and that of a credible individual in general. 
To further contextualise the inclination of forensic professionals away from the hyperbolic, and towards the literal, the work of Shonna Trinch needs consideration. Trinch (2010) explores the incident-reporting of paralegal interviewers with clients who are victims of domestic assault. Her analysis adeptly identifies two things: first, that victims quote-often and verbatim—abusive and obscene language used by their perpetrator in order to be successfully perceived as victims and credible narrators. Second, paralegal interviewers often dissolve these direct quotes and replace them with distanced language to create the narrative of a witness - one who detaches themselves from the abuse and objectively views their perpetrator's actions. While Trinch's (2010) work does not refer to hyperbole, her observations explicate the results of this study, especially in relation with the response of the specialist participants. While lay participants seemed to resonate with the very tool complainants used to make themselves seem more credible, forensic professionals had a stronger leaning towards their occupational cultivation of creating distanced, legally credible narratives which are often less affective, hence more literal.

The primary aim of the current study was to test hyperbolic conversations in legal settings to determine the consequences of hyperbole in instances involving serious crime. The results of this study are critical because in Experiment 1, the hyperbolic victims should ideally have implied emotional distress (thus increasing sympathy among participants and portraying the victim as more impacted) - the depiction of which has proved beneficial in literature - since emotional behaviour cannot be depicted without language (Lakoff, 2016). However, the hyperbolic victims suffered in comparison to their non-hyperbolic counterparts and this goes against some of the theories - like the affect control theory (Heise, 1987) - about a victim's behaviour expectation. Findings from Experiment 2 are continually congruent with 
this theory. While hyperbole had no impact on likability, victims seemed significantly more impacted when they used hyperbole as observed by non-specialist participants. It is however important to note that believability was only significantly impacted when data were averaged across participants, but not when they were averaged across scenarios.

While there is minimal research on the perception of figurative speech in forensic settings, there is a lot of insight into the perception of emotional behaviour (Bollingmo et al., 2009; Kaufmann et al., 2003; Rose et al., 2006; Rose \& Nadler, 2002). The data from those studies show that a victim's emotional behaviour (and consequently language) heavily contribute to victim perception, credibility, and requirement of an additional expert witness. These factors in turn have impact on prosecution, which is the ultimate outcome of all forensic proceedings, and hence language considerations are important, albeit being secondary or indirect factors.

\subsection{Limitations}

It is important to note that the scenarios in this study were predominantly narratives and contain limited evaluations. Hyperbole occurs frequently in negative evaluations, and hence using scenarios/transcripts that focused on participants' evaluations as opposed to a chain of events might have yielded a more positive reaction to hyperbole in the sympathy and victim-impact measures. However, evaluations are often not necessary or desirable when first describing crimes to authorities, whereas narratives of the actual chain of events are essential and often determining in legal situations.

Like a majority of research investigating language, the scenarios, while based on real narratives, were essentially fabricated in order to allow manipulation for empirical purposes. This severely limits naturally occurring creative metaphorical 
hyperbole in discourse (e.g. "I was beaten to look like a bag of mulberries") which by virtue of being metaphorical, have no suitable literal counterpart available to manipulate (Carston \& Wearing, 2015).

Another limitation is the inclusion of $(0)$ on the rating scale. While allowing participants to hedge, and providing the study with more accurate portrayals of participants' perception, it is a choice that can only be provided in academic settings. In forensic settings, all individuals concerned with the case (jury, judge or law enforcement) must make clear dichotomous choices.

\section{Conclusions}

Hyperbole in victim statements has a significant negative impact on belief, sympathy, victim-impact, as well as likability when the participants are specialists within the forensics field. In contrast, hyperbole has a positive impact on belief and victim-impact when participants are members of the general population with no background in forensics. Non-specialist participants were more perceptive of the clear target of emotion as well as its non-neutral nature. This may also be evidence that while non-specialist participants closely perceive hyperbole as a tool for linguistic expression, specialist participants go a step further and also evaluate the probability of psychological presence of emotion, as opposed to a mere linguistic expression. Future studies will look at the different levels of hyperbole (realistic, possible but improbable, and the impossible) and attempt to investigate whether some levels of hyperbole are perceived more or less positively than others. 


\section{References}

Adams, S. H. (1996). Statement analysis: What do suspects' words really reveal. FBI Law Enforcement Bulletin, 65, 12.

Anderson, K. J., \& Leaper, C. (1998). Emotion talk between same-and mixed-gender friends: Form and function. Journal of Language and Social Psychology, 17, 419448.

Andrus, J. (2009). The development of an artefactual language ideology: Utterance, event, and agency in the metadiscourse of the excited utterance exception to hearsay. Language \& Communication, 29(4), 312-327.

Andrus, J. (2011). Beyond texts in context: Recontextualization and the co-production of texts and contexts in the legal discourse, excited utterance exception to hearsay. Discourse \& Society, 22(2), 115-136.

Andrus, J. (2012). Language ideology, fractal recursivity, and discursive agency in the legal construction of linguistic evidence. Language in Society, 41(5), 589-614.

Ask, K., \& Granhag, P. A. (2005). Motivational sources of confirmation bias in criminal investigations: The need for cognitive closure. Journal of Investigative Psychology and Offender Profiling, 2, 43-63.

Ask, K., \& Landström, S. (2010). Why emotions matter: Expectancy violation and affective response mediate the emotional victim effect. Law and Human Behavior, 34, 392-401.

Baldry, A.C., \& Winkel, F.W. (1998). Perceptions of the credibility and evidential value of victim and suspect statements in interviews. In J. Boros, I. Munnich, \& M. Szegedi (Eds.), Psychology and criminal justice: International review of theory and practice (pp. 74-82). Berlin: De Gruyter 
Bandes, S. (2017). Empathy, narrative, and victim impact statements. In Nussbaum and Law (pp. 225-276). Routledge.

Bergelson, V. (2005). Victims and perpetrators: An argument for comparative liability in criminal law. Buffalo Criminal Law Review, 8, 385-487.

Bogoch, B. (2007). The victim as 'other': Analysis of the language of acquittal decisions in sexual offences in the Israeli Supreme Court. In The Language of Sexual Crime (pp. 159-179). London: Palgrave Macmillan.

Bollingmo, G. C., Wessel, E. O., Eilertsen, D. E., \& Magnussen, S. (2008). Credibility of the emotional witness: A study of ratings by police investigators. Psychology, Crime \& Law, 14, 29-40.

Bollingmo, G., Wessel, E., Sandvold, Y., Eilertsen, D. E., \& Magnussen, S. (2009). The effect of biased and non-biased information on judgments of witness credibility. Psychology, Crime \& Law, 15, 61-71.

Boucher, J., \& Osgood, C. E. (1969). The Pollyanna hypothesis. Journal of Verbal Learning and Verbal Behavior, 8, 1-8.

Bowes, A., \& Katz, A. (2011). When sarcasm stings. Discourse Processes, 48, 215236.

Boylan, J., \& Katz, A. N. (2013). Ironic expression can simultaneously enhance and dilute perception of criticism. Discourse Processes, 50, 187-209.

Burgers, C., Brugman, B. C., Renardel de Lavalette, K. Y., \& Steen, G. J. (2016). HIP: A method for linguistic hyperbole identification in discourse. Metaphor and Symbol, 31, 163-178.

Cano Mora, L. (2004). At the Risk of Exaggerating: How Do Listeners React to Hyperbole? Anglogermanica Online: Revista Electrónica Periódica de Filología Alemana e Inglesa, 2, 2-13. 
Cano Mora, L. (2009). All or nothing: A semantic analysis of hyperbole. Revista de Lingüística y Lenguas Aplicadas, 4, 25-35.

Carston, R., \& Wearing, C. (2015). Hyperbolic language and its relation to metaphor and irony. Journal of Pragmatics, 79, 79-92.

Carter, R., \& McCarthy, M. (1997). Exploring spoken English (Vol. 2). Cambridge University Press.

Christie, N. (1986). The ideal victim. In E. Fattah (Ed.), From crime policy to victim policy (pp. 17-30). London: Palgrave Macmillan.

Claridge, C. (2010). Hyperbole in English: A corpus-based study of exaggeration. Cambridge: Cambridge University Press.

Coates, L., Bavelas, J. B., \& Gibson, J. (1994). Anomalous language in sexual assault trial judgments. Discourse \& Society, 5, 189-206.

Colston, H. L., \& Keller, S. B. (1998). You'll never believe this: Irony and hyperbole in expressing surprise. Journal of Psycholinguistic Research, 27, 499-513.

Danet, B. (1980). Language in the Courtroom. In H. Giles, P. Robinson, \& P. Smith (Eds.), Language (pp. 367-376). Oxford: Pergamon Press Ltd.

Ehrlich, S. (2007). Normative discourses and representations of coerced sex. The language of sexual crime (pp. 126-138). London: Palgrave Macmillan.

Ekman, P. (1993). Facial expression and emotion. American Psychologist, 48, 384.

Ekman, P. (1997). Deception, lying, and demeanor. In D. F. Halpern \& A. E. Voiskounsky (Eds.), States of mind: American and post-Soviet perspectives on contemporary issues in psychology (pp. 93-105). Oxford University press.

Estrich, S. (1987). Real rape. Harvard University Press. 
Filik, R., Țurcan, A., Thompson, D., Harvey, N., Davies, H., \& Turner, A. (2016).

Sarcasm and emoticons: Comprehension and emotional impact. The Quarterly Journal of Experimental Psychology, 69, 2130-2146.

Frohmann, L. (1991). Discrediting victims' allegations of sexual assault: Prosecutorial accounts of case rejections. Social Problems, 38, 213-226.

Gibbs Jr, R. W., Gibbs, R. W., \& Gibbs, J. (1994). The poetics of mind: Figurative thought, language, and understanding. Cambridge: Cambridge University Press.

Grice, H. P. (1957). Meaning. The Philosophical Review, 66, 377-388.

Gruber, A. (2003). Victim wrongs: The case for a general criminal defense based on wrongful victim behavior in an era of victims' rights. Temple Law Review, 76, 645.

Heise, D. R. (1987). Affect control theory: Concepts and model. Journal of Mathematical Sociology, 13, 1-33.

Hills, A. M., \& Thomson, D. M. (1999). Should victim impact influence sentences? Understanding the community's justice reasoning. Behavioral Sciences \& The Law, 17, 661-671.

Kaufmann, G., Drevland, G. C., Wessel, E., Overskeid, G., \& Magnussen, S. (2003). The importance of being earnest: Displayed emotions and witness credibility. Applied Cognitive Psychology, 17, 21-34.

Kreuz, R. J., \& Glucksberg, S. (1989). How to be sarcastic: The echoic reminder theory of verbal irony. Journal of Experimental Psychology: General, 118, 374.

Kreuz, R. J., \& Roberts, R. M. (1995). Two cues for verbal irony: Hyperbole and the ironic tone of voice. Metaphor and Symbol, 10, 21-31.

Lakoff, G. (2016). Language and emotion. Emotion Review, 8, 269-273.

Larcombe, W. (2002). The ideal victim v successful rape complainants: Not what you might expect. Feminist Legal Studies, 10, 131-148. 
Leggitt, J. S., \& Gibbs, R. W. (2000). Emotional reactions to verbal irony. Discourse Processes, 29, 1-24.

Loftus, E. F., \& Palmer, J. C. (1974). Reconstruction of automobile destruction: An example of the interaction between language and memory. Journal of Verbal Learning and Verbal Behavior, 13, 585-589.

Maier, S. L. (2008). “I Have Heard Horrible Stories..." Rape Victim Advocates' Perceptions of the Revictimization of Rape Victims by the Police and Medical System. Violence Against Women, 14, 786-808.

Maier, S. L. (2014). Rape, victims, and investigations: Experiences and perceptions of law enforcement officers responding to reported rapes. Routledge.

Maglione, G. (2017). Embodied victims: An archaeology of the 'ideal victim' of restorative justice. Criminology \& Criminal Justice, 17, 401-417.

Matoesian, G. M., (2000). Intertextual authority in reported speech: Production media in the Kennedy Smith rape trial. Journal of Pragmatics, 32(7), 879-914.

Matoesian, G. M., (2001). Law and the language of identity: Discourse in the William Kennedy Smith rape trial. Oxford University Press on Demand.

McCarthy, M., \& Carter, R. (2004). "There's millions of them": hyperbole in everyday conversation. Journal of Pragmatics, 36, 149-184.

Memon, A. A., Vrij, A., \& Bull, R. (2003). Psychology and law: Truthfulness, accuracy and credibility. John Wiley \& Sons.

Nadler, J., \& Rose, M. R. (2002). Victim impact testimony and the psychology of punishment. Cornell Law Review, 88, 419.

Nair, R. B. (1985). Telling lies: some literary and other violations of Grice's maxim of quality. Nottingham Linguistic Circular, 14, 53-90. 
Nemesi, A. L. (2010). Data-gathering methods in research on hyperbole production and interpretation. In E. T. Németh \& K. Bibok (Eds.), The Role of Data at the Semantics-Pragmatics Interface (pp. 381-417). New York: De Gruyter Mouton.

Norrick, N. R. (2004). Hyperbole, extreme case formulation. Journal of Pragmatics, 9, 1727-1739.

Phelps, E. A. (2004). Human emotion and memory: interactions of the amygdala and hippocampal complex. Current Opinion in Neurobiology, 14, 198-202.

Pickering, B., Thompson, D., \& Filik, R. (2018). Examining the emotional impact of sarcasm using a virtual environment. Metaphor and Symbol, 33, 185-197.

Ponterotto, D. (2007). The repertoire of complicity vs. coercion: The discursive trap of the rape trial protocol. In The language of sexual crime (pp. 104-125). London: Palgrave Macmillan.

Quintilian, M. F. (1921). Institutio oratoria (HE Butler, Trans.). New York: GP Putnam's Sons.

Roberts, R. M., \& Kreuz, R. J. (1994). Why do people use figurative language? Psychological Science, 5, 159-163.

Rose, M. R., Nadler, J., \& Clark, J. (2006). Appropriately upset? Emotion norms and perceptions of crime victims. Law and Human Behavior, 30, 203-219.

Sinclair, J. M., \& Coulthard, M. (1975). Towards an analysis of discourse: The English used by teachers and pupils. Oxford University Press.

Spears, J. W., \& Spohn, C. C. (1997). The effect of evidence factors and victim characteristics on prosecutors' charging decisions in sexual assault cases. Justice Quarterly, 14, 501-524. 
Spohn, C., Beichner, D., \& Davis-Frenzel, E. (2001). Prosecutorial justifications for sexual assault case rejection: Guarding the "gateway to justice". Social Problems, 48, 206-235.

Stevenson, K. (2000). Unequivocal victims: The historical roots of the mystification of the female complainant in rape cases. Feminist Legal Studies, 8, 343-366.

Süssenbach, P., Bohner, G., \& Eyssel, F. (2012). Schematic influences of rape myth acceptance on visual information processing: An eye-tracking approach. Journal of Experimental Social Psychology, 48, 660-668.

Trinch, S. (2010). Disappearing discourse: Performative texts and identity in legal contexts. Critical Inquiry in Language Studies, 7(2-3), 207-229.

Tsoudis, O. (2002). The influence of empathy in mock jury criminal cases: Adding to the affect control model. Western Criminology Review, 4, 55.

Tsoudis, O., \& Smith-Lovin, L. (1998). How bad was it? The effects of victim and perpetrator emotion on responses to criminal court vignettes. Social Forces, 77, 695-722.

Van Wijk, J. (2013). Who is the 'little old lady' of international crimes? Nils Christie's concept of the ideal victim reinterpreted. International Review of Victimology, 19, 159-179.

Wessel, E. M., Bollingmo, G. C., Sønsteby, C., Nielsen, L. M., Eilertsen, D. E., \& Magnussen, S. (2012). The emotional witness effect: Story content, emotional valence and credibility of a male suspect. Psychology, Crime \& Law, 18, 417-430. Willbern, D. (1989). Rape, Writing, Hyperbole: Shakespeare's Lucrece. Compromise Formations: Current Directions in Psychoanalytic Criticism, 183-198. 
Winkel, F. W., \& Koppelaar, L. (1991). Rape victims' style of self-presentation and secondary victimization by the environment: An experiment. Journal of Interpersonal Violence, 6, 29-40.

Young, A. (1998). The waste land of the law, the wordless song of the rape victim. Melbourne University Law Review, 22, 442. 